www.jmscr.igmpublication.org

Impact Factor 5.84

Index Copernicus Value: 83.27

ISSN (e)-2347-176x ISSN (p) 2455-0450

crossref DOI: _https://dx.doi.org/10.18535/jmscr/v5i8.129

\title{
Comparison of Intrathecal Bupivacaine with and without Fentanyl for Transurethral Resection of Prostate
}

\author{
Author \\ Sheeba Franklin \\ Associate professor, Department of Anaesthesiology, Government Medical College, Kottayam, Kerala \\ Corresponding Author \\ Sheeba Franklin \\ Njondimackal, Thellakom.P.O, Kottayam \\ Telephone no; 0481-2791655, Email: sheebabinu04@gmail.com
}

\begin{abstract}
Background: Opioids are being increasingly used these days as adjuvants to local anesthetics in spinal anaesthesia. The aim of this study is to compare the effects of adding fentanyl to low dose bupivacaine in spinal anesthesia for Transurethral Resection of Prostate (TURP).

Methods: In this prospective, randomized double-blind study, spinal anaesthesia was performed in 50 American Society of Anesthesiologists I-III patients aged 55-90 years old, undergoing Transurethral Resection of Prostate using 10mg hyperbaric bupivacaine 0.5\%- $2 \mathrm{ml}$ (Group A) or by adding fentanyl $25 \mu \mathrm{g}$ (Group B) to $9 \mathrm{mg}$ hyperbaric bupivacaine 0.5\%-2 $\mathrm{ml}$ (Group B). These groups were compared in terms of the quality of spinal anaesthesia as well as analgesia. The primary outcome was time to 2 segment regression and corresponding motor block. Secondary outcomes were time to reach maximal upper sensory level, maximal level of sensory block, and corresponding degree of motor block. Haemodynamic variables were also assessed.

Results: The onset of motor blockade was significantly rapid in Group II as compared with Group I. Quality of analgesia was significantly better and prolonged in fentanyl group as compared with lowdose bupivacaine alone group $(P=0.000)$. The maximum upper level of sensory block was higher in Group II patients than Group I patients. $(P=0.023)$. Motor block was more intense and more prolonged in fentanyl group as compared with Group I patients. The median (minimum, maximum) time to attain maximum level of upper sensory block was $5(2,10)$ and $4(2,6)$ minutes for low - dose bupivacaine and for low-dose bupivacaine with fentanyl respectively. Mean maximal level was T6-T7 and T5-T6 for low - dose bupivacaine and for low - dose bupivacaine with fentanyl respectively. Duration of block above T10 was $44(30,60)$ and $63(30,80)$ minutes for Group I and Group II respectively $(P=0.000)$.

Conclusions: Spinal anaesthesia in elderly patients using low dose bupivacaine $(10 \mathrm{mg})$ combined with $25 \mu \mathrm{g}$ fentanyl is associated with a lower incidence of haemodynamic instability, better quality and prolonged duration.
\end{abstract}

Keywords: Low-Dose Bupivacaine, Fentanyl, Transurethral Resection of Prostate. 


\section{Introduction}

Trans-urethral resection of prostate (TURP) ${ }^{[1]}$ is one of the common surgical procedures. It is still considered as the gold standard treatment of benign prostatic hyperplasia $(\mathrm{BPH})$, which induces urinary obstruction and consequently, increases the risk of urinary tract infection. This kind of surgery is mostly performed for patients with prostate weight less than 60 grams .TURP may have several complications before and after surgery ${ }^{[1]}$. Some of them are TURP syndrome, bladder rupture and prostate capsule perforation. Early detection of such complications depends on preserving the level of consciousness during the operation; thus, spinal anaesthesia ${ }^{[1]}$ is preferred over general anaesthesia in TURP.

Spinal anaesthesia for patients undergoing transurethral resection of prostate (TURP) is very commonly used. Most patients posted for TURP are elderly and frequently having cardiopulmonary, endocrine, or other comorbidities ${ }^{[1]}$. Thus, it is important to limit the block level to minimize haemodynamic changes during the spinal anaesthesia in such patients. Low-dose local anaesthetics can limit the spinal block level and induce rapid recovery from anaesthesia. Intrathecal opioids ${ }^{[1,2,3,7]}$ or clonidine are frequently administered as adjuvants with local anaesthetics to improve the anaesthetic quality and postoperative analgesia ${ }^{-}$

It was seen that in elderly patients, severe hypotension $^{[1]}$ can occur following spinal anaesthesia, which may be due to sympathetic nerve blockade. Furthermore, bradycardia, urinary retention and neurological injuries can be mentioned as complications of spinal anaesthesia ${ }^{[1]}$, which is mostly dependent on the volume and dose of injection as well as the level of spinal block. Thus, to minimize such complications, especially in elderly patients ${ }^{(5,6,8)}$ with less compensatory capabilities, anaesthesia with appropriate duration, dosing of drugs and minimal complications is needed to be preferred.

The aim of this study was to compare the characteristics of spinal block, haemodynamic changes, and postoperative analgesia, following administration of intrathecal $25 \mu \mathrm{g}$ fentanyl ${ }^{[1,19,15]}$ combined with low-dose bupivacaine in elderly patients undergoing TURP.

\section{Materials and Methods}

In this randomized double-blind study, 50 patients in the age group of 55-90 years, belonging to American Society of Anesthesiologists (ASA) physical status I and III, scheduled for elective transurethral resection of prostate surgery under spinal anaesthesia, were included . A written informed consent was obtained from each patient. Patients with a history of spine surgery or the presence of an infectious focus on the back, coagulopathy, hypersensitivity to local anaesthetics, cooperation difficulty, heart block/ dysrrhythmia or neurological disorders, morbid obesity were excluded from the study.

Depending upon the nature of Intrathecal drug used, these patients were randomized into two groups of 25 patients each, as:Group A: Subarachnoid block with $0.5 \%$ hyperbaric bupivacaine $10 \mathrm{mg}(2 \mathrm{ml})$.Group B: Subarachnoid block with $0.5 \%$ hyperbaric bupivacaine $9 \mathrm{mg}$ (1.8 $\mathrm{ml})+$ Fentanyl $25 \mu \mathrm{g}(0.2 \mathrm{ml})$ Total $2 \mathrm{ml}$.

Routine pre-anaesthetic check-up comprising of general physical examination, systemic examination and routine investigations of all patients was conducted a day before surgery.

All patients were premedicated with tablet diazepam $10 \mathrm{mg}$. After shifting the patient to the operating table, monitoring of heart rate, noninvasive blood pressure, respiratory rate and electrocardiography and oxygen saturation was done. An intravenous line was secured and patients were preloaded with isotonic saline 5 $\mathrm{ml} / \mathrm{kg}$ body weight over a period of 15-20 min. The fluid was minimally infused during the surgery to avoid overloading associated with the systemic absorption of irrigating fluid.

Under strict aseptic conditions, lumbar puncture was performed at the level of L 3-4 or L 4-5 intervertebral space using $25 \mathrm{G}$ spinal needle in the lateral decubitus position. After obtaining a 
free flow of cerebrospinal fluid, $2 \mathrm{ml}$ study drug was injected intrathecally at approximately 0.25 $\mathrm{ml} / \mathrm{s}$ and patient was made supine immediately.

\section{Clinical Assessment}

The primary end-point of this study was the time to the regression of 2-dermatomes from the peak sensory block level. The secondary end-points were the maximum upper level of sensory block and the time taken to attain maximum upper level and corresponding motor block.

Level of sensory block was determined on the bilateral mid-clavicular line with a pin-prick every 2 min from the time of drug injection until the maximum level reached.The peak block level was defined as the same block level that persisted for four consecutive tests. The degree of motor block was scored using the Modified Bromage scale $(0=$ able to move the hip, knee, and ankle; $1=$ unable to move the hip, but able to move the knee and ankle; $2=$ unable to move the hip and knee, but able to move the ankle; $3=$ unable to move the hip, knee, and ankle). Mean arterial pressure (MAP) and heart rate (HR), respiratory rate (RR) were measured every $2 \mathrm{~min}$ for $20 \mathrm{~min}$. Respiratory depression was defined as a respiratory rate of $\leq 8$ breaths per minute and oxygen saturation of $\leq 85 \%$ in room air. The peak sensory block level, time to reach the maximum upper sensory level of block, motor block grade at peak sensory block, and in the recovery room, the time to the sensory regression of 2dermatomes and corresponding motor block scales were recorded.

Data are presented as mean (S.D) or numbers as appropriate. Patient characteristics like age, body mass index, sex, duration of operation, were analyzed using two way ANOVA test, time to peak block, time to 2-dermatomes regression were analyzed using the independent $t$-test. Maximum motor block scalewas analyzed by Mann-Whitney $U$-test. $\mathrm{P}$ values $<0.05$ were interpreted as statistically significant.

\section{Results}

Demographic data of this study were statistically comparable as regards to age, sex, weight, height, type of surgery and ASA physically status (Table $1)$. Thirty-nine of fifty patients had more than one systemic disease, such as hypertension $(n=34)$, diabetes mellitus $(n=30)$, coronary artery disease $(n=6)$, cerebrovascular accident $(n=2)$, chronic obstructive pulmonary disease $(n=36)$, and chronic renal failure $(n=12)$.

Table I; Demographic Data

\begin{tabular}{|l|c|c|c|}
\hline Parameters & Group I & Group II & P value \\
\hline Age in years & $68.3+9.5$ & $66.0+9.5$ & 0.407 \\
\hline Body mass index (BMI) & $24.8+3.4$ & $24.7+3.1$ & 0.953 \\
\hline Duration of surgery (min) & $32.0+18.7$ & $28.2+10.3$ & 0.388 \\
\hline Sex (M:F)(n) & $31: 19$ & $25: 25$ & 0.235 \\
\hline
\end{tabular}

Data represented as Mean \pm SD. Group I; bupivacaine alone.Group II; bupivacaine with fentanyl

Table 2 Intraoperative variation of heart rate

\begin{tabular}{|l|c|c|c|}
\hline & Group I & Group II & P value \\
\hline Baseline HR & $64.7+10.5$ & $72.8+12.6$ & 0.001 \\
\hline Five minutes after spinal & $63.0+8.9$ & $72.4+9.1$ & \\
\hline Ten minutes after spinal & $64.6+8.9$ & $70.6+7.9$ & \\
\hline Fifteen minutes after spinal & $60.5+8.9$ & $66.5+10.3$ & \\
\hline Twenty minutes after spinal & $63.1+9.0$ & $64.7+6.8$ & \\
\hline Sixty minutes after spinal & $61.9+6.9$ & $69.2+5.6$ & \\
\hline Postoperative HR after 30 min & $60.0+4.8$ & $71.2+6.8$ & \\
\hline
\end{tabular}
$\begin{aligned} & \text { Data represented as mean+SD.Group I; bupivacaine alone .Group II; } \\
& \text { bupivacaine with fentanyl. }\end{aligned}$

The baseline values were comparable $(\mathrm{P}=0.524)$ between the two groups (Table 2).The mean HR was significantly more in the Group II $(69.6 \pm 1.3)$ than in the Group I $(69.6 \pm 1.4)$ and this difference was significant with $\mathrm{P}=0.001$. There was a decline in the mean heart rate across observation times and this decline was also significant with. $\mathrm{P}=0.000$. The interactionwas also significant $\mathrm{P}=0.007$.This means that the course of decline was not the same in the two groups and decrease was more in Fentanyl group.

Table 3; Intraoperative variation of mean arterial pressure

\begin{tabular}{|l|c|c|c|}
\hline & Group I & Group II & P value \\
\hline Baseline MAP & $97.0+21.1$ & $86.6+9.7$ & 0.032 \\
\hline Five minutes after spinal & $88.5+6.9$ & $83.4+7.8$ & \\
\hline Ten minutes after spinal & $86.4+6.1$ & $83.8+5.3$ & \\
\hline Fifteen minutes after spinal & $83.0+3.1$ & $84.0+6.8$ & \\
\hline Twenty minutes after spinal & $86.5+3.6$ & $83.4+6.4$ & \\
\hline Sixty minutes after spinal & $88.8+5.0$ & $85.0+4.9$ & \\
\hline Postoperative MAP after 30 min & $91.1+6.7$ & $87.0+5.1$ & \\
\hline $\begin{array}{l}\text { Data represented as the mean } \pm \text { SD. Group I; bupivacaine alone. Group II; } \\
\text { bupivacaine with fentanyl. }\end{array}$
\end{tabular}


The baseline values were comparable $(\mathrm{P}=)$ between the two groups (Table 3). The mean MAP was significantly lower in the Group II $(88.8 \pm 1.0)$ than the Group I $(84.8 \pm 0.98)$ and this difference was significant, $\mathrm{P}=0.007$. There was a decline in the mean MAP across different time periods up to 15 minutes observation and then increased. This change was also significant $\mathrm{P}=.000$. The interaction was also significant $\mathrm{P}=0.001$ indicating that the changes were not uniform in both the groups.

The baseline values of respiratory rate were comparable $(\mathrm{P}=0.5801)$ between the two groups. The changes in the mean RR across different time periods was significant $\mathrm{P}=0.003$. The interaction was not significant.

Table 4; Sensory block characteristics

\begin{tabular}{|l|c|c|c|}
\hline Parameters & Group I & Group II & Pvalue \\
\hline $\begin{array}{l}\text { Time to attain maximum upper } \\
\text { level of sensory block(minutes) }\end{array}$ & $5.3 \pm 2.3$ & $3.6 \pm 1.4$ & 0.004 \\
\hline Duration of sensory block(minutes) & $44.4 \pm 9.2$ & $58.1 \pm 12.3$ & 0.000 \\
\hline $\begin{array}{l}\text { Number of patients with maximum } \\
\text { upper level of sensory block }\end{array}$ & & & 0.899 \\
\hline T2-T4 & 4 & 9 & \\
\hline T5-T6 & 8 & 11 & \\
\hline T7-T8 & 7 & 5 & \\
\hline T9-T10 & 6 & 0 & \\
\hline
\end{tabular}

Group II showed a shorter time to reach the peak sensory block level and a longer time to reach the 2-segment regression compared to Group I. Duration of sensory block was significantly prolonged in Group II $(\mathrm{P}<0.01)$ (Table 4). The mean time (S.D.) to the sensory regression of 2dermatomes was $44.4 \pm 9.2 \mathrm{~min}$ and $58.1 \pm 12.3 \mathrm{~min}$ in the bupivacaine group and bupivacaine with fentanyl group respectively. Maximum upper level of sensory block was higher in group II compared to group I. Number of patients in Group II with a sensory block above T4 was higher compared to Group I ( $\mathrm{P}=0.033)$.

Table 5 motor block characteristics

\begin{tabular}{|l|c|c|c|}
\hline & Group I & Group II & P Value \\
\hline $\begin{array}{l}\text { Number of patients with modified Bromage score grade at upper } \\
\text { sensory level }\end{array}$ \\
\hline Bromage score 0 & 1 & 4 & 0.023 \\
\hline Bromage score 1 & 9 & 11 & \\
\hline Bromage score 2 & 11 & 8 & \\
\hline Bromage score 3 & 4 & 2 & \\
\hline $\begin{array}{l}\text { Number of patients with modified Bromage score at two segment } \\
\text { regression }\end{array}$ \\
\hline Bromage score 0 & 2 & 1 & 0.000 \\
\hline Bromage score 1 & 9 & 0 & \\
\hline Bromage score 2 & 13 & 12 & \\
\hline Bromage score 3 & 1 & 12 & \\
\hline
\end{tabular}

Independent $\mathrm{t}$ test for time and Mann Whitney $\mathrm{U}$ for grade data

In Modified Motor Block scale, Group II had higher scale especially at the regression of 2dermatomes than Group I ( $\mathrm{P}=0.000)$ (Table 5). Onset of motor block was quicker in Group II as compared to Group I with a median time of onset of 4 minutes in Group II and 5 minutes in Group I. In Group I, $16 \%$ patients had modified Bromage score of 3 and $44 \%$ patients had modified Bromage score of 2.In Group II, $8 \%$ patients had modified Bromage score of 3 and $32 \%$ patients had modified Bromage score of 2 .

Figure I quality of motor block at peak sensory block

Quality of motor block

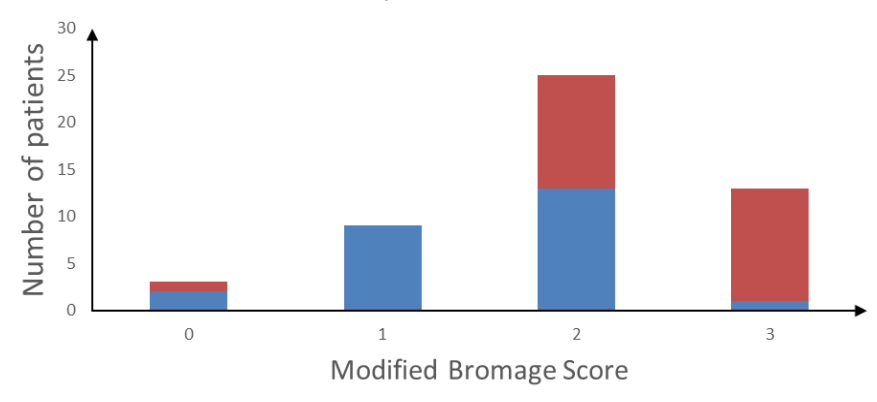

- GROUP I - GROUP II

Figure II maximum upper sensory level

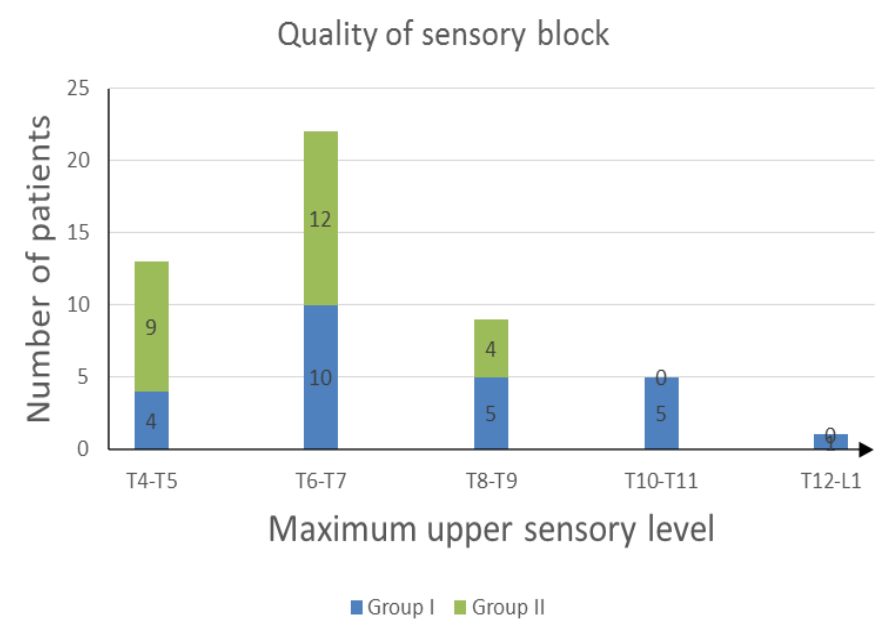

\section{Discussion}

Bupivacaine, an amide type local anaesthetic, has high potency, slow onset and long duration of action but has been associated with prolonged motor block, central nervous system and cardiac 
toxicity. Opioid analogues ${ }^{(2,7,9)}$ have been used as additives in spinal anaesthesia to improve the onset of action, prolong the duration of block and to improve the quality of perioperative analgesia. Fentanyl, a lipophilic opioid has a rapid onset and short duration of action following intrathecal administration

The primary end-point of this study was the time to regression of 2-sensory dermatomes from the peak sensory block level. In the current study, it was observed that $25 \mu \mathrm{g}$ of intrathecal fentanyl significantly prolonged the duration of sensory block compared to the low-dose bupivacaine control group. The time to reach peak block level was also shorter in the fentanyl group than in the control group. In addition, despite similar peak sensory block levels for the two groups, motor block scales were significantly higher in the fentanyl group.

Patients undergoing TURP are usually elderly ${ }^{(5,6,8)}$ having various co-morbidities. Thus, it is important to limit the block level to minimize the hemodynamic instability during spinal anaesthesia. Therefore, the dose of intrathecal local anesthetic should be decreased to limit the block level. In our institute, $10 \mathrm{mg}$ bupivacaine has been used to obtain short duration of block and rapid return of motor function in elderly patients undergoing TURP.

Morphine was the first opioid to be used intrathecally, but a wide variety of clinically relevant side-effects, especially respiratory depression is seen .A favorable pharmacokinetic and pharmacodynamic profile of lipophilic opiates e.g. fentanyl and sufentanil, makes them better alternatives, because of a rapid uptake, faster onset and shorter duration of action. This minimizes the rostral migration of the drug to the respiratory center, avoiding delayed respiratory depression. Sufentanil, a pure agonists is an N-4 thienyl derivative of fentanyl. It is considered to be more lipid soluble, a better receptor ligand and is 7-10 times more potent analgesic than fentanyl. Lee et $\mathrm{al}^{[18]}$ used $10 \mathrm{mg}$ isobaric bupivacaine and $10 \mathrm{mg}$ isobaric ropivacaine with $15 \mu \mathrm{g}$ fentanyl for urological surgery. They observed that all patients achieved sensory block upto T10 dermatome or higher after $15 \mathrm{~min}$ of intrathecal injection and cephalad spread of sensory block was higher in bupivacaine group than ropivacaine group. Thus, it was found that $25 \mu \mathrm{g}$ fentanyl could be appropriate for intrathecal dose with $9 \mathrm{mg}$ bupivacaine.

In the current study, $25 \mu \mathrm{g}$ of fentanyl with $9 \mathrm{mg}$ bupivacaine somewhat increased the peak sensory block level compared to the control group and did prolong the duration of sensory block. Although, there was no significant difference in peak sensory block level between bupivacaine group and bupivacaine adding fentanyl group, all patients in fentanyl group had a sensory level above T10 which was thought to be adequate for TURP.

In our study, Modified Bromage Score 3 (complete motor block) was seen only in $4 \%$ of patients in group I, while it was in $48 \%$ of patients in fentanyl group at the end of operation. This shows that the degree of motor block was more intense in the fentanyl group. Though we did not evaluate the duration of motor block, this indicates that small dose of fentanyl can potentiate the degree of motor block. As seen in Group II, fentanyl prolongs not only the duration of sensory block, but also the degree and duration of the motor block.

The time required to reach maximum height of the block was significantly more in fentanyl group $(5.3 \pm 2.3 \mathrm{~min})$ as compared to plain bupivacaine group (3.6 $\pm 1.4 \mathrm{~min})$. However, Kim et al., showed no significant difference in time to peak block level (15.4 min in fentanyl group and $15.1 \mathrm{~min}$ in sufentanil group) ${ }^{(2)}$.

Addition of opioids to low dose bupivacaine definitely improves the analgesic effect and also leads to a significant beneficial effect of early ambulation because of minimal motor block. Kararmaz et al., demonstrated significantly prolonged motor block in plain bupivacaine group as compared to fentanyl with low dose bupivacaine in elderly patients undergoing TURP (16). Soni et al, also concluded that low dose 
intrathecal ropivacaine $(3 \mathrm{mg})$ with sufentanil (10 $\mu \mathrm{g})$ improved quality and duration of analgesia without impairing the motor strength during labor $^{(13,14,)}$, to facilitate early ambulation ${ }^{(17)}$.

None of the patients in Group I and three patients in GroupII had hypotensive episodes. They were given increments of mephenteramine $6 \mathrm{mg}$ intravenously and an infusion of $500 \mathrm{ml}$ normal saline. One of the patient in group II had bradycardia. He was given atropine $0.6 \mathrm{mg}$ intravenously.

To conclude, spinal anaesthesia with low dose bupivacaine $(9 \mathrm{mg}$ ) when combined with $25 \mu \mathrm{g}$ fentanyl provides adequate anaesthesia for TURP surgery in elderly patients and is associated with a lower incidence of haemodynamic instability when compared to spinal anaesthesia with $10 \mathrm{mg}$ bupivacaine $(0.5 \%)$ alone. If intensity of motor block is required for longer duration, then bupivacaine - fentanyl is a better choice.

\section{Sources of support in the form of grants: nil}

\section{References}

1. Hong JY, Yang SC, Ahn S, Kil HK. Preoperative comorbidities and relationship of comorbidities with postoperative complications in patients undergoing transurethral prostate resection .Journal of Urology.185, 1374-1378 (2011).

2. Kim SY,CHO JE, Koo BN, Kim JM, Kil HK. Comparison of intrathecal fentanyl and sufentanil in low-dose dilute bupivacaine spinal anaesthesia for transurethral prostatectomy British Journal of Anaesthesia; 103, 750-754 (2009).

3. Ben-David B, Solomon E, Levin $\mathrm{H}$, Admoni H, Goldik Z. Intrathecal fentanyl with small-dose dilute bupivacaine: better anesthesia without prolonging recovery. Anesthesia Analgesia 85, 560-565 (1997).

4. Shesky MC, Rocco AG, Bizzarri-Schmid M, Francis DM, Edstrom H, Covino BG.
A dose-response study of bupivacaine for spinal anesthesia. Anesthesia Analgesia 62, 931-935 (1983).

5. Ruppen W, Steiner LA, Drewe J, Hauenstein L, Brugger S, Seeberger MD. Bupivacaine concentrations in the lumbar cerebrospinal fluid of patients during spinal anaesthesia. British Journal of Anaesthesia. 102, 832-838 (2009)

6. Veering BT, Immink-Speet TTM, Burm AGL, Stienstra R, van Kleeef JW. Spinal anaesthesia with $0.5 \%$ hyperbaric bupivacaine in elderly patients: effects of duration spent in the sitting position. British Journal of Anaesthesia, 87, 738742 (2001).

7. Akcoboy EY, Akcaboy ZN, Gogus N. Low dose levobupivacaine $0.5 \%$ with fentanyl in spinal anaesthesia for transurethral resection of prostate surgery. J. Res. Med. Sci., 16, 68-73 (2011).

8. 8)Erdil F, Bulut S, DerDemirbilek S, Gedik E, Gulhas N, Ersoy MO. The effects of intrathecal levobupivacaine and bupivacaine in the elderly. Anaesthesia, 64, 942-946 (2009).

9. Kuusniemi KS, Pihlajamaki KK, Pitkanen MT, Helenius HY, Kirvela OA. The use of bupivacaine and fentanyl for spinal anesthesia for urologic surgery. Anesthesia Analgesia91, 1452-1456 (2000).

10. De Kock M, Gautier P, Fanard L, Hody JL, Lavand'homme P. Intrathecal ropivacaine and clonidine for ambulatory knee arthroscopy: a dose-response study. Anesthesiology, 94, 574-578 (2001).

11. Mohamed AA, Fares KM, Mohamed SA. Efficacy of intrathecally administered dexmedetomidine versus dexmedetomidine with fentanyl in patients undergoing major abdominal cancer surgery. Pain Physician, 15, 339-348 (2012).

12. Al-Ghanem SM, Massad IM, Al-Mustafa MM, Al-Zaben KR, Qudaisat IY, Qatawneh AM, Abu-Ali HM. Effect of 
adding dexmedetomidine versus fentanyl to intrathecal bupivacaine on spinal block characteristics in gynecological procedures: A double blind controlled study. American Journal of Applied Sciences, 6, 882-887 (2009).

13. Palmer CM, Cork RC, Hays R, Van Maren G, Alves D. The dose-response relation of intrathecal fentanyl for labor analgesia. Anesthesiology. 1998;88:355-61.

14. Nelson KE, Rauch T, Terebuh V, D' Angelo R. A comparison of intrathecal fentanyl and sufentanil for labor analgesia. Anesthesiology. 2002;96:1070-3.

15. Gupta R, Verma R, Bogra J, Kohli M, Raman R, Kushwaha JK. A comparative study of intrathecal dexmedetomidine and fentanyl as adjuvants to bupivacaine. Journal of Anaesthesiology Clinical Pharmacology, 27, 339-343 (2011).

16. Kararmaz A, Kaya S, Turhanoglu S, Ozyilmaz MA. Low-dose bupivacainefentanyl spinal anaesthesia for transurethral prostatectomy. Anaesthesia. 2003;58:526-30.

17. Soni AK, Miller CG, Pratt SD, Hess PE, Oriol NE, Sarna MC. Low dose intrathecal ropivacaine with or without sufentanil provides effective analgesia and does not impair motor strength during labor: A pilot study. Canadian Journal of Anaesthesia. 2001;48:677-80.

18. Lee YY, Ngan Kee WD, Muchhal K, Chan CK. Randomized double blind comparison of Ropivacaine Fentanyl and Bupivacaine Fentanyl for spinal anaesthesia for urological surgery. Acta Anaesthesiol Scand 2005; 49: 1477-82. 